\title{
PAMAM Dendrimer Conjugated with N-terminal Oligopeptides of Mouse Fibroblast Growth Factor 3 as a Novel Gene Carrier
}

\author{
Jinwoo Jung, ${ }^{\dagger}$ Jeil Lee, ${ }^{\dagger}$ Tae-Hun Kim, ${ }^{\dagger}$ Bong Suk Yang, ${ }^{\dagger}$ Eunji Lee, ${ }^{\dagger}$ Youn-Joong Kim, ${ }^{\S}$ \\ Jong-Sang Park,,$^{\#, *}$ and Joon Sig Choi ${ }^{\dagger, *}$ \\ ${ }^{\dagger}$ Graduate School and Department of Analytical Science and Technology (GRAST), \\ Chungnam Nationl University, Daejeon 305-764, Korea \\ ¿Department of Biochemistry, College of Natural Sciences, Chungnam National University, \\ Daejeon 305-764, Korea. E-mail: joonsig@cnu.ac.kr \\ ${ }^{\S}$ Korea Basic Science Institute (KBSI) Gwahangno (52 Yeoeun-Dong), Yuseong-Gu, Daejeon 305-333, Korea \\ ${ }^{\#}$ School of Chemistry and Molecular Engineering, Seoul National University, Seoul 151-742, Korea \\ *E-mail: pfjspark@plaza.snu.ac.kr \\ Received November 11, 2013, Accepted December 6, 2013
}

\begin{abstract}
In this study, we introduced the RRLR oligopeptide sequences on the surface of polyamidoamine (PAMAM) dendrimer and characterized the physical properties and gene carrier activity of the novel polymer using HEK 293, NIH3T3, and HeLa cells. The RRLR peptide sequences were derived from a mouse fibroblast growth factor 3 (FGF3) protein containing a bipartite NLS motif. The entire sequence of FGF3 is RLRRDAGGRGGVYEHLGGAPRRRK and it has two functional sequences RLRR and RRRK at Nterminus and C-terminus, respectively. In particular, PAMAM G4-RRLR conferred enhanced transfection efficiency and lower cytotoxicity compared with those of PEI $25 \mathrm{kDa}$, PAMAM G4-R, and PAMAM G4 in various cell lines. These results suggest that the introduction of N-terminal oligopeptides of FGF3 on the surface of PAMAM holds promise as an effective non-viral gene delivery carrier for gene therapy.
\end{abstract}

Key Words : Gene delivery, PAMAM dendrimer, Peptide, Mouse fibroblast growth factor 3

\section{Introduction}

Gene therapy is a promising approach to treat several genetic disorders, which are difficult to treat using other methods. Gene delivery may be achieved using viral and non-viral vectors. Viral vectors exhibit greater transfection efficiency because of viral infection capacity, but their use in clinical practice is restrictive because of hyperactive immune response and mutational risks. ${ }^{1,2}$ In the recent years, to overcome these problems, several research groups have used non-viral vectors such as cationic polymers and lipids for gene delivery. ${ }^{1-4}$ The use of non-viral methods is of potential interest as they are simple, flexible, stable, and relatively safe compared to the viral vectors. Non-viral delivery carriers such as cationic polymers and lipids interact with the negatively charged plasmid DNA and form complexes, which are transferred to the cell. However, the crucial limitations of these non-viral vectors are their poor transfection efficiency and cytotoxicity. ${ }^{5}$ Currently, the cationic polymers polyethyleneimine (PEI) and polyamidoamine (PAMAM) have gained significant interest as effective DNA carriers. PEI exhibits high transfection efficiency in various cell lines, but it has strong cytotoxicity owing to the cationic amine groups and the lack of biodegradable linkers. ${ }^{1,4}$ PAMAM is a dendrimer consisting of biodegradable peptide bonds, with an ethylenediamine (EDA) core and is formed by repetitive Michael addition and amidation reaction using methyl acrylate and EDA. ${ }^{1,4,6,7}$ PAMAM dendrimer displays a spherical structure containing secondary and tertiary amines, and indicates excellent biocompatibility and low cytotoxicity. Therefore, PAMAM has been used as an attractive material for gene delivery by many research groups. To overcome the poor transfection efficiency, which was also shown to be cell-type dependent, many research groups tried conjugating it with cell-specific ligands, cell penetrating peptides (CPPs), and nuclear localization signal (NLS) peptides. ${ }^{8,9,14}$

In our previous study, we utilized the RRRK segment on the surface of PAMAM. ${ }^{10}$ The RRRK peptide sequence is one of such bipartite NLS motifs originated from a mouse fibroblast growth factor 3 (FGF3) and PAMAM derivatives conjugated with RRRK peptides showed outstanding transfection efficiency in fibroblast cells.

In this study, we introduced NLS at the peripheral ends of PAMAM dendrimer. The NLS peptides guide active transportation and facilitated translocation of the polymer/DNA complexes into the nucleus. ${ }^{9}$ We used the RLRR sequence of one of the bipartite NLS peptides originated from FGF3. ${ }^{11}$ We conjugated the RLRR peptide sequences to the peripheral ends of PAMAM dendrimer and performed experiments to determine the biophysical properties and biological functions, such as transfection efficiency and cytotoxicity, of the conjugate in HEK293, HeLa, and NIH3T3 cells.

\section{Experimental Sections}

Materials and Reagents. Polyamidoamine dendrimer 
(PAMAM, generation 4), ethidium bromide (EtBr), $N, N$ dimethylformamide (DMF), dimethyl sulfoxide (DMSO), $N, N$-diisopropylehylamine (DIPEA), trifluoroacetic acid (TFA), and triisopropylsilane (TIS) were purchased from Sigma-Aldrich (Seoul, South Korea). PicoGeen reagent, Alexa Fluor 488 protein labeling kit and Alexa fluor 532 nucleic acid labeling kit was obtained from Molecular Probes (Invitrogen). $\mathrm{N}$-Hydroxybenzotriazole (HOBt), 2(1H-benzotriazole-1-yl)-1,1,3,3-tetramethyluronium (HBTU), Fmoc-Arg(pbf)-OH and Fmoc-Leu-OH were purchased from Anaspec (San Jose, CA, USA). EZ-cytox was purchased from Daeil lab service (Seoul, South Korea). Luciferase assay kit was and lysis buffer were obtained from Promega (Madison, WI, USA). Fetal bovine serum (FBS), Dulbecco's modified Eagle's medium (DMEM), 100× antibiotic-antimycotic reagent were purchased from GIBCO (Gaithersburg, MD, USA). Micro BCA protein assay kit was purchased from Pierce (Rockford, IL, USA). HEK293, HeLa and NIH3T3 cell lines were obtained from Korean Cell Line Bank.

Synthesis of PAMAM G4-Arg-Arg-Leu-Arg Conjugate. Synthesis of amino acids at the peripheral end of PAMAM generation 4(G4) was achieved by adding four equivalents of Fmoc-Arg(pbf)-OH, HOBt, HBTU, and eight equivalents of DIPEA in mixture of anhydrous DMF and DMSO of 2:1 $(\mathrm{v} / \mathrm{v})$ to PAMAM G4 in a reaction cocktail for $16 \mathrm{~h}$ at room temperature (R.T.). The intermediate product was precipitated in cold ethyl ether and washed with excess ether. The Fmoc groups of amino acids in the conjugated PAMAM G4 were removed by adding $30 \%$ piperidine in $\mathrm{DMF}(\mathrm{v} / \mathrm{v})$ to the reaction mixture for $2 \mathrm{~h}$. Then, the intermediate product was precipitated in cold ethyl ether and washed. To conjugate Fmoc-Leu-OH, the intermediate product was incubated with four equivalents of Fmoc-Leu-OH, HOBt, HBTU, and eight equivalents of DIPEA in anhydrous DMF for $16 \mathrm{~h}$ at R.T. Then, as mentioned above, additional conjugation of amino acids and removal of Fmoc groups were performed and eliminated. The deprotection of pbf groups containing arginines was performed using the TFA solution (a v/v solution of trifluoracetic acid, triisopropylsilane, $\mathrm{H}_{2} \mathrm{O}$, in a ratio of $95: 2.5: 2.5$, respectively) for reaction of $6 \mathrm{~h}$ at R.T. Then, the product was precipitated in cold ethyl ether and washed. To further purify unwanted materials, the final product was placed in a dialysis membrane (MWCO 3,500, Spectra/por) and dialyzed with distillated water for $24 \mathrm{~h}$. Then, the final product was obtained after lyophilization for $16 \mathrm{~h}$. The overall scheme for synthesis and coupling of amino acids to the PAMAM G4 is described in Figure 1. The total yield of synthesized products was generally over $95 \%$ and ${ }^{1} \mathrm{H}$ NMR spectra $\left(600 \mathrm{MHz}, \mathrm{D}_{2} \mathrm{O}\right)$ of the synthesized polymers are displayed in Figure 2.

Gel Retardation Assay and PicoGreen Assay. PAMAM G4-RRLR/plasmid DNA (pDNA) complexes were formed at various weight ratios ranging from 1 to 10 in HEPES buffer ( $25 \mathrm{mM}, \mathrm{pH} 7.4$ ) for $30 \mathrm{~min}$ at R.T. After $30 \mathrm{~min}$, the samples were analyzed on a $0.7 \%$ agarose gel with ethidium bromide $(0.5 \mu \mathrm{g} / \mathrm{mL})$. Agarose gel electrophoresis was performed for $20 \mathrm{~min}$ at $100 \mathrm{~V}$. In the picogreen assay, polyplexes of PAMAM G4-RRLR and pDNA $(0.5 \mu \mathrm{g})$ were

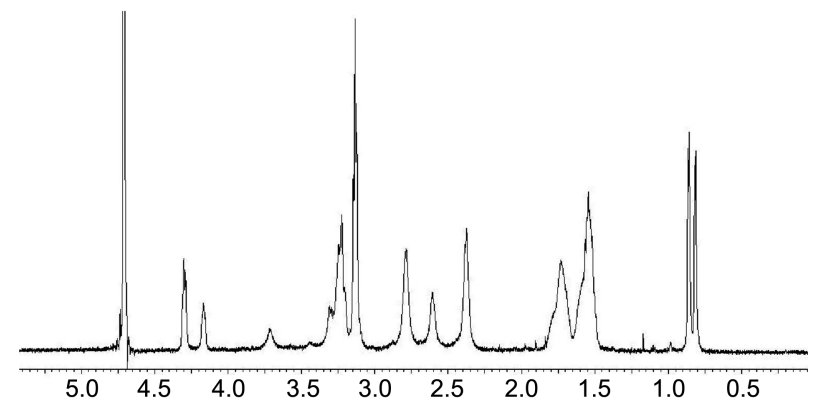

Figure 2. ${ }^{1} \mathrm{H}$ NMR of PAMAM G4-Arg-Arg-Leu-Arg.
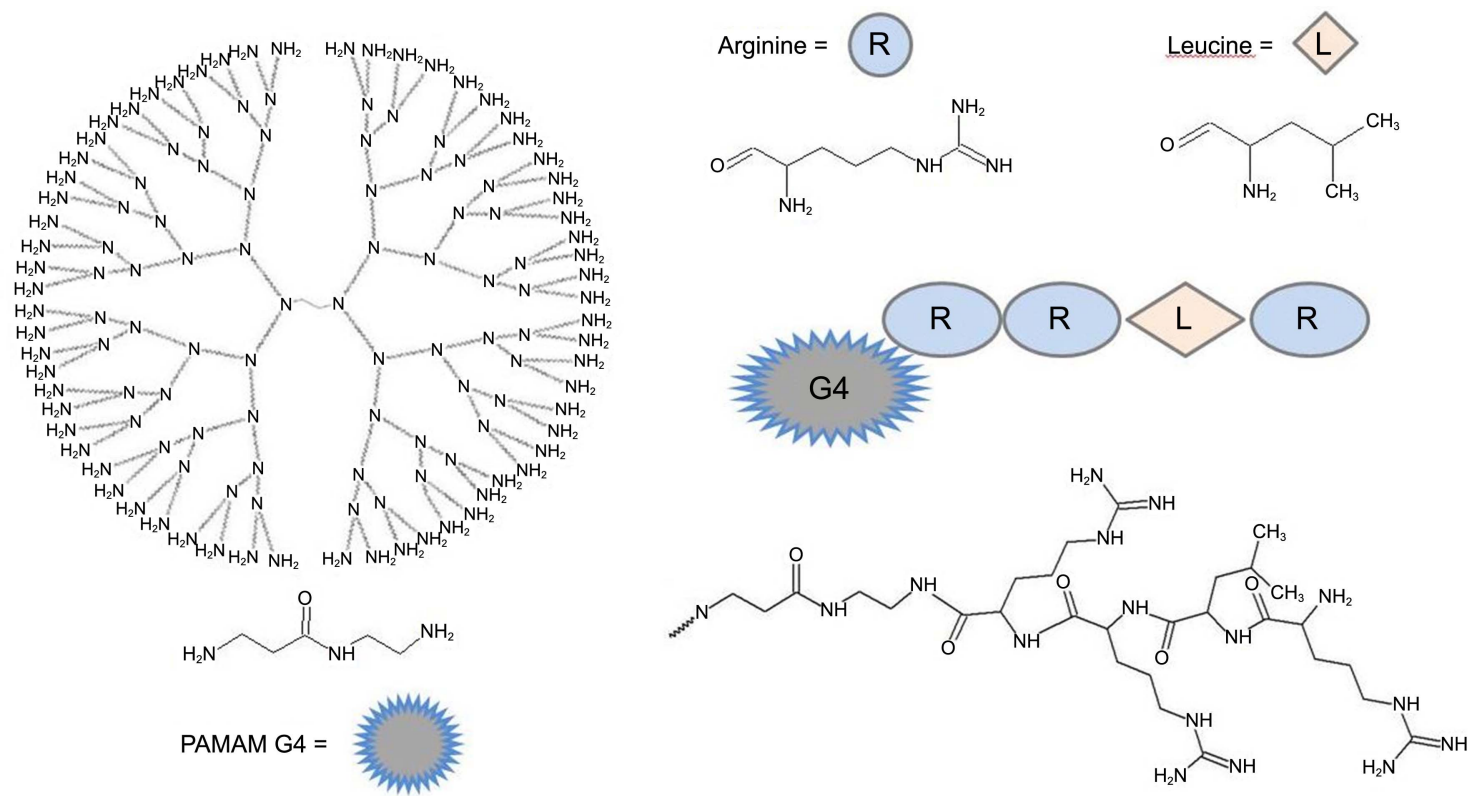

Figure 1. Molecular structure of PAMAM G4-RRLR. 
prepared at weight ratios of range from 0.5 to 4.0 , in $200 \mu \mathrm{L}$ of HEPES buffer ( $25 \mathrm{mM}, \mathrm{pH} 7.4$ ), and incubated for $30 \mathrm{~min}$ at R.T. Then, $200 \mu \mathrm{L}$ of the picogreen reagent diluted in TE buffer (10 mM Tris-HCl, 1 mM EDTA, pH 7.4) was added. The mixture of polyplexes with diluted picogreen reagent was prepared by volume of total $2 \mathrm{~mL}$. The measurement of fluorescence intensity was determined by using spectrofluorometer (Quantech Digital Filter Fluorometer, Thermo Scientific, USA, excitation-490 nm and emission-520 nm).

Particle Size and $\zeta$-Potential Measurements. The particle size and $\zeta$-Potential values of polyplexes were measured by a Zeta-potential \& Particle Size Analyzer ELS-Z (Photal, Otsuka Electronics, Japan) and Zetasizer Nano ZS (Malvern Instruments, UK). Under weight ratio indicating the optimal transfection efficiency, polyplexes were prepared by volume of total $1 \mathrm{~mL}$ in distilled water.

Transmission Electron Microscopy Experiments. PAMAM G4-RRLR/pDNA (24:1, w/w) complexes were prepared and incubated for $30 \mathrm{~min}$ at R.T. After $30 \mathrm{~min}$, the prepared polyplex of $10 \mu \mathrm{L}$ was placed on the 300 mech copper grid and dried for $12 \mathrm{~h}$ in the atmosphere. Electron micrographs were analyzed by an energy filtering transmission electron

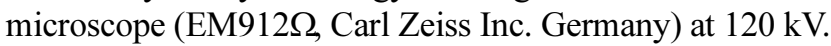

Cell Culture and In Vitro Transfection. Human embryonic kidney (HEK) 293 cells, murine fibroblast NIH3T3 cells, and human epithelial carcinoma (HeLa) cells were cultured in DMEM with $10 \%$ FBS and $1 \%$ antibiotics. Cell lines were maintained on T25 plask in an incubator $\left(5 \% \mathrm{CO}_{2}\right.$, $95 \%$ humidity, $37^{\circ} \mathrm{C}$ ). For the transfection studies, cells seeded at a density of $1.8 \times 10^{4}$ cells/well in a 96-well flatbottomed microassay plates for $18 \mathrm{~h}$ to $70-80 \%$ confluence. Polyplexes of PAMAM G4-RRLR with pDNA were prepared in various weight ratios. To compare the transfection efficiency, polypexes of PEI 25kDa, PAMAM G4, PAMAM G4-R with pDNA were used as the control group. The cells were treated with polyplexes and incubated for $24 \mathrm{~h}\left(5 \% \mathrm{CO}_{2}, 95 \%\right.$ humidity, $\left.37^{\circ} \mathrm{C}\right)$. The cells were washed by Dulbecco's Phosphate Buffered Saline (DPBS) and reporter lysis buffer (Promega) of $100 \mu \mathrm{L}$ was treated in cells and incubated for $30 \mathrm{~min}$. Then, the cells were harvested, transferred to microcentrifuge tubes, and centrifuged at 13,200 rpm for $10 \mathrm{~min}$. Luciferase activity was measured in terms of relative light units (RLU) using a Lumat LB 9507 (Berthold Technology, Bad Wildbad, Germany) and the protein concentration of extracts was measured by a Micro BCA protein assay kit.

Cytotoxicity Assay. For evaluation of cytotoxicity assay, WST-1 assay was performed. Cells were seeded at a density of $1.8 \times 10^{4}$ cells/well in 96-well plates and cultured in media of $100 \mu \mathrm{L}$ for $18 \mathrm{~h}$ in an incubator $\left(5 \% \mathrm{CO}_{2}, 95 \%\right.$ humidity, $\left.37^{\circ} \mathrm{C}\right)$. Then, the cells were treated with various concentrations of PEI 25kDa, PAMAM G4, PAMAM G4-R, and PAMAM G4-RRLR and were incubated for $24 \mathrm{~h}$ at $37{ }^{\circ} \mathrm{C}$. Then, $10 \mu \mathrm{L}$ Ez-Cytox Reagent was added to each well and incubated for 2 at $37^{\circ} \mathrm{C}$. The absorbance was measured at $450 \mathrm{~nm}$ using a microplate reader (VeraMax, Molecular Devices, Sunnyvale, CA, USA).

Confocal Microscopy Experiments. Alexa Fluor 532- labeled pDNA and Alexa Fluor 488- labeled polymer were prepared according to the manufacture's protocol. HeLa cells were seeded at a density of $5 \times 10^{3}$ cells/well on a confocal dish and incubated for $16 \mathrm{~h}$ at $37{ }^{\circ} \mathrm{C}$. Then, Alexa Fluor 532labeled pDNA and unlabeled pDNA were mixed at 1:1 (w/w) and the mixed DNA was incubated with Alexa Fluor 488-labeled PEI 25 kDa, PAMAM G4, PAMAM G4-R, and PAMAM G4-RRLR. The weight ratio of respective prepared polyplexes was prepared as optimal transfection efficiency. After a further incubation for $24 \mathrm{~h}$, nuclei were stained with $10 \mu \mathrm{g} / \mathrm{mL}$ bisbenzimide (Hoechst 33342) for $20 \mathrm{~min}$ and washed with PBS several times. The cells were analyzed using a confocal laser-scanning microscopy (Zeiss LSM 5 Live confocal laser microscope).

\section{Results and Discussion}

Synthesis of PAMAM G4-RRLR. The synthetic yield of the PAMAM G4-RRLR was estimated by calculating the indispensable values of the peaks. As illustrated in Figure 2, the PAMAM G4-RRLR was confirmed by ${ }^{1} \mathrm{H}$ NMR (600 $\left.\mathrm{MHz}, \mathrm{D}_{2} \mathrm{O}\right)$.

PAMAM G4-RRLR Conjugates: The following are the NMR chemical shift data for the PAMAM G4 conjugates : $\delta 0.815\left(-\mathrm{CHCH}_{2} \mathrm{CH}\left(\mathrm{CH}_{3}\right)_{2}-\right.$ of the leucine peak $), 0.86$ $\left(-\mathrm{CHCH}_{2} \mathrm{CH}\left(\mathrm{CH}_{3}\right)_{2}\right.$ - of the leucine peak), $1.54\left(-\mathrm{CHCH}_{2}\right.$ $\mathrm{CH}_{2} \mathrm{CH}_{2} \mathrm{NH}$ - of the arginine peak and $-\mathrm{CHCH}_{2} \mathrm{CH}\left(\mathrm{CH}_{3}\right)_{2}-$ of the leucine peak), $1.73\left(-\mathrm{CHCH}_{2} \mathrm{CH}\left(\mathrm{CH}_{3}\right)_{2}\right.$ - of the leucine peak and $-\mathrm{CHCH}_{2} \mathrm{CH}_{2} \mathrm{CH}_{2} \mathrm{NH}$ - of the arginine peak), 2.37 (- $\mathrm{NCH}_{2} \mathrm{CH}_{2} \mathrm{CO}$ - of PAMAM peak), 2.61 (-CONHCH $\mathrm{CH}_{2} \mathrm{~N}-$ of PAMAM peak and - $\mathrm{NCH}_{2} \mathrm{CH}_{2} \mathrm{~N}$ - of PAMAM peak), 2.79 (-CONHCH $\mathrm{CH}_{2} \mathrm{~N}$ - of PAMAM peak and $-\mathrm{NCH}_{2} \mathrm{CH}_{2} \mathrm{~N}$ - of PAMAM peak), $3.13\left(-\mathrm{CHCH}_{2} \mathrm{CH}_{2} \mathrm{CH}_{2} \mathrm{NH}\right.$ - of the arginine peak), 3.24 (-CONHCH $\mathrm{CH}_{2} \mathrm{~N}$ - of PAMAM peak). The number of conjugated RLRR peptides was calculated from ${ }^{1} \mathrm{H}$ NMR data. Approximately 63 molecules of RLRR peptides were introduced to a single PAMAM G4.

Gel Retardation Assay and PicoGreen Assay. To confirm the stability of PAMAM G4-RRLR - pDNA complexes, we performed agarose gel retardation and picogreen assays (Figure 3). The retardation of prepared polyplexes was analyzed in $0.7 \%$ agarose gel and the PAMAM G4-RRLR and pDNA formed intact polyplexes at ratios between 2:1 and 4:1 (w/w) in Figure 3(a). To verify the specific point of polyplex formation, we used picogreen reagent as a sensitive and effective probe. As shown in Figure 3(b), PAMAM G4RRLR and pDNA formed complete polyplexes at the optimal ration of $2: 1(\mathrm{w} / \mathrm{w})$.

Dynamic Light Scattering and $\zeta$-Potential Measurements of Polyplexes. Particle size and $\zeta$-potential are significant factors influencing cellular uptake, transfection efficiency and cytotoxicity. ${ }^{12,13}$ Cationic polymers potentially condense and neutralize the negatively charged pDNA and assist its interaction with the negatively charged cellular membrane. However, once polymer/pDNA complex reaches more than $30 \mathrm{mV}$, it is shown to induce cytotoxicity. ${ }^{12,14} \mathrm{We}$ analyzed the average diameters and $\zeta$-potential of the polymer/pDNA 
(a)

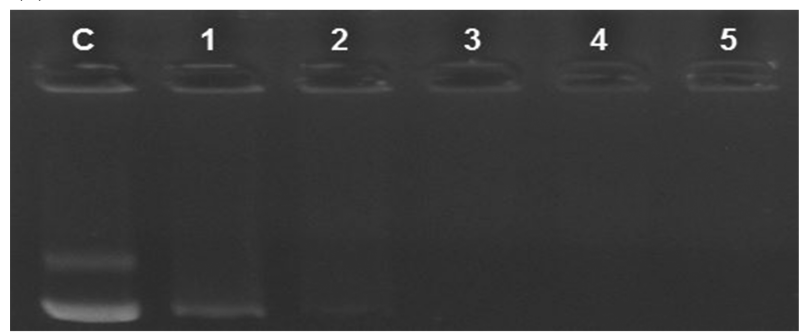

(b)

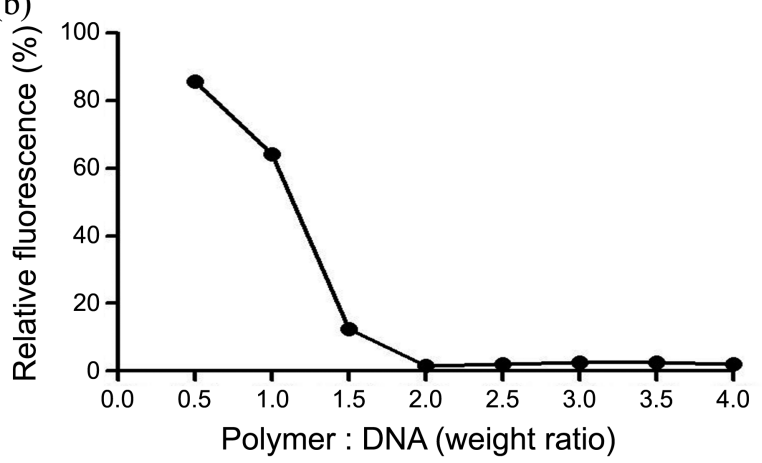

Figure 3. Agarose gel retardation and picogreen assay of polyplexes. (a) Agarose gel retardation assay. pDNA only (lane 1), the weight ratios of PAMAM G4-RRLR/pDNA = 1, 2, 4, 8, 10 (lane 1-5). (b) PicoGreen reagent assay at various weight ratios. (PAMAM G4RRLR/pDNA $=0.5,1.0,1.5,2.0,2.5,3.0,3.5,4.0)$
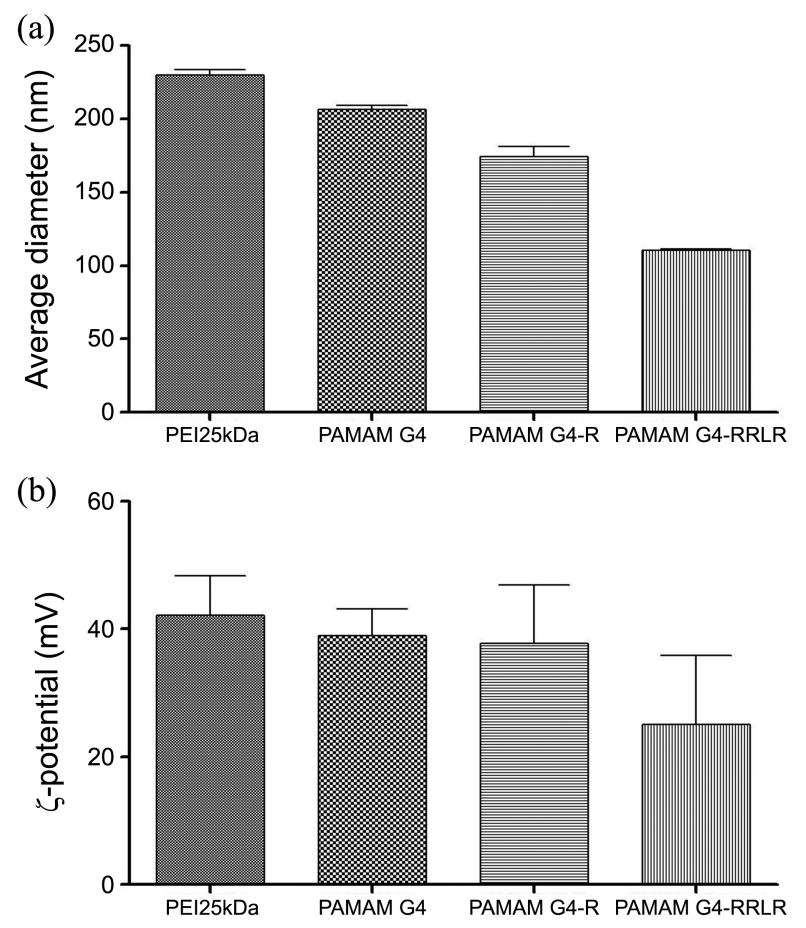

Figure 4. Size and $\zeta$-Potential analysis of polyplexes. (a) Average diameter of particle using dynamic light scattering and (b) Zeta potential values of polymer/pDNA complexes. Date are shown as mean \pm standard deviation $(\mathrm{n}=3)$.

complexes to optimize the transfection efficiency and the results are presented in Figure 4. The size of polymer/pDNA complexes range between 110 and $230 \mathrm{~nm}$ average diameter
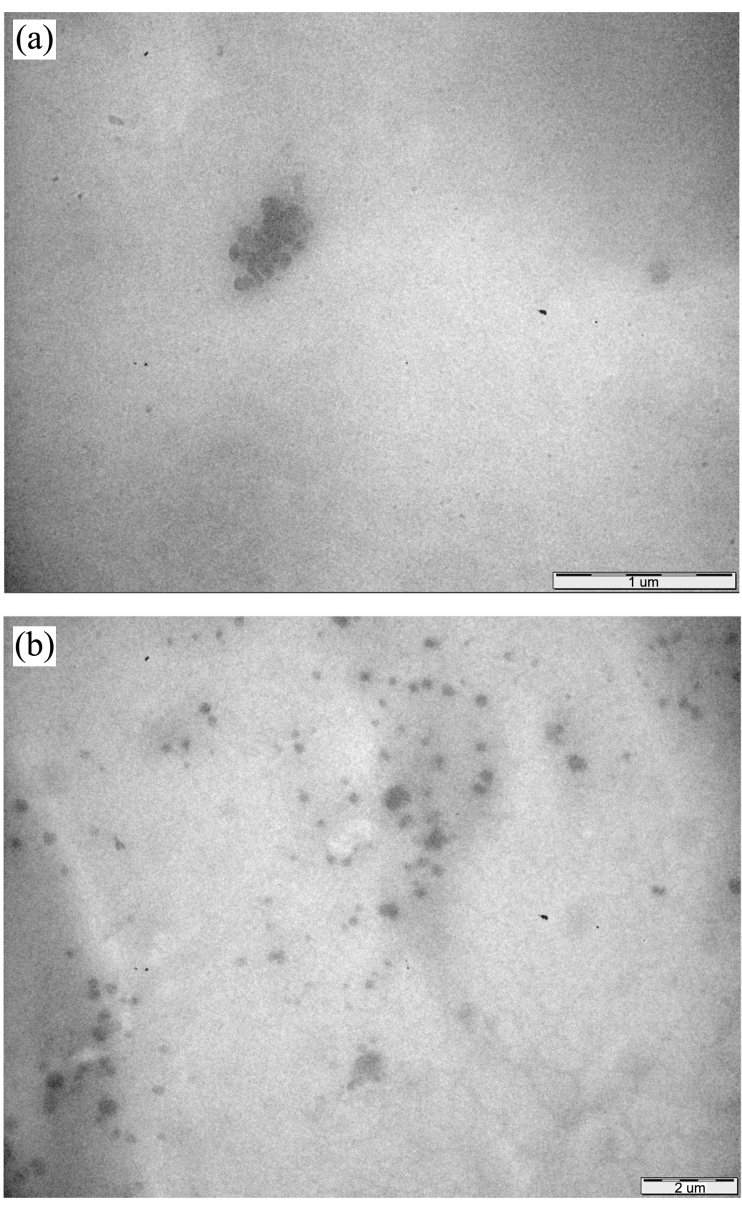

Figure 5. Transmission electron microscopy (TEM) image of (a) PAMAM G4/pDNA = 4:1, (b) PAMAM G4-RRLR/pDNA = 24:1.

and the $\zeta$-potential value of polymer/pDNA complex was found to be between 25 and $42 \mathrm{mV}$. Interestingly, the size and $\zeta$-potential value of native PAMAM G4/pDNA polyplexes (4:1, w/w) and PAMAM G4-R/pDNA (16:1, w/w) polyplexes were approximately $200 \mathrm{~nm}$ and $39 \mathrm{mV}$, and $170 \mathrm{~nm}$ and 37 $\mathrm{mV}$, respectively. The PAMAM G4-RRLR/pDNA (24:1, $\mathrm{w} / \mathrm{w})$ polyplexes were $110 \mathrm{~nm}$ in diameter and had $\zeta$-potential value of $25 \mathrm{mV}$. Although many arginines were introduced on the surface of PAMAM G4, the relatively small particle size and low $\zeta$-potential value of the synthesized molecules might be due to their unique structural properties and an increase in DNA condensation capacity contributed by the basic amino acids.

Transmission Electron Microscopy. To observe the particle morphology and size, the PAMAM G4-RRLR/pDNA polyplexes $(24: 1, \mathrm{w} / \mathrm{v})$ were observed using transmission electron microscopy. ${ }^{15,16}$ As shown in Figure 5, polyplexes were represented round. Although their mean diameter was not similar to those measured using dynamic light scattering, we could elucidate the approximate size of polyplexes and the discrepancy in these results from different methods might be due to condensation between polyplexes during the airdrying process.

Transfection Efficiency and Cytotoxicity Assay Results. To evaluate the transfection efficiency, PAMAM G4-RRLR/ 
(a)

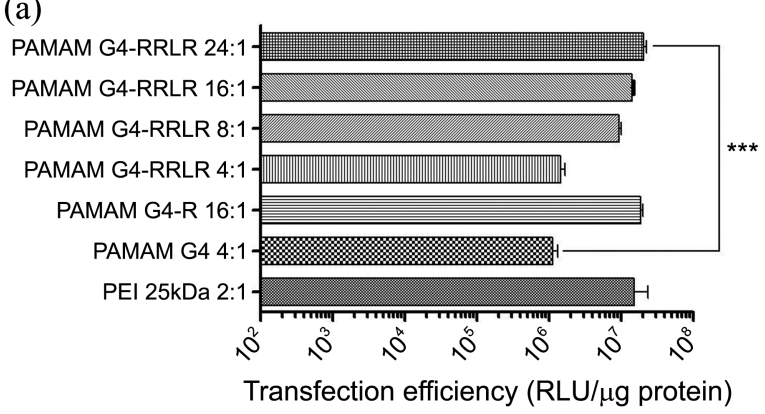

(b)

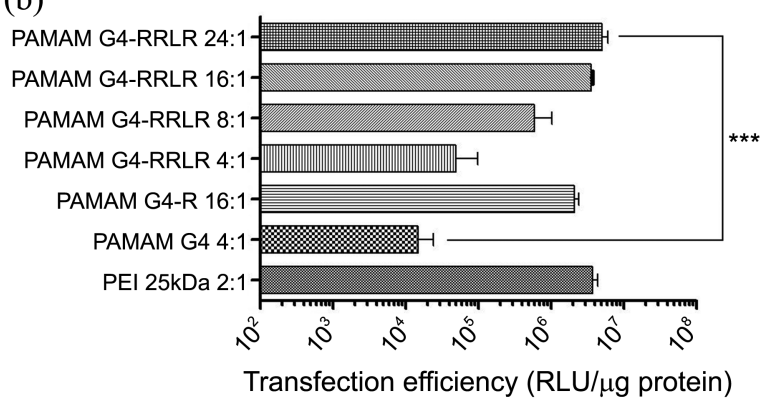

(c)

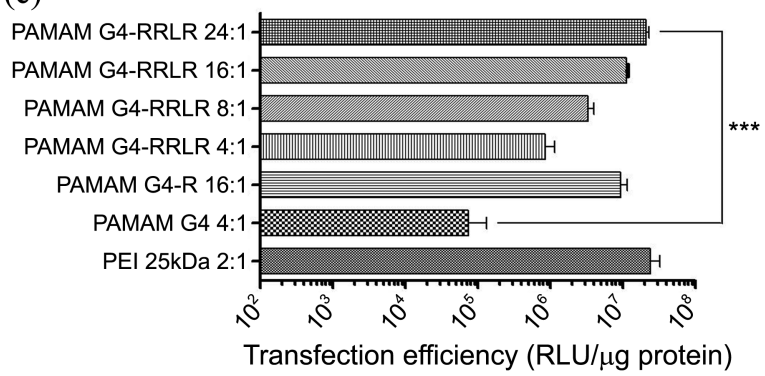

Figure 6. In vitro transfection efficiency of PAMAM G4-RRLR. (a) HEK293, (b) NIH3T3 and (c) HeLa cells. Each value is the mean \pm standard deviation $(\mathrm{n}=3) . * * * \mathrm{p}<0.001$.

pDNA complexes were transfected into HEK293, NIH3T3, and HeLa cells at varying weight ratios in the presence of $10 \%$ serum. Transfection efficiency was estimated by the luciferase expression and the protein concentration of the cell lysate. PEI $25 \mathrm{kDa}(2: 1, \mathrm{w} / \mathrm{w})$, native PAMAM G4 (4:1, $\mathrm{w} / \mathrm{w})$, and PAMAM G4-R (16:1, w/w) were utilized as controls. PEI was known to facilitate a high transfection efficiency as assessed by the higher gene expression levels and according to our previous study, PAMAM G4-R exhibited similar transfection efficiency levels as observed with PEI. ${ }^{17}$ As shown in Figire 6, PAMAM G4-RRLR (24:1, w/w) showed higher transfection efficiency in all cells than the original PAMAM G4 and showed transfection efficiency similar to PEI $25 \mathrm{kDa}$ and PAMAM G4-R. To verify the cytotoxicity of respective polymers, we performed WST-1 assay in HEK 293, NIH3T3, and HeLa cells. The PEI 25 $\mathrm{kDa}$, PAMAM G4, and PAMAM G4-R were utilized as controls. Each of these cells were seeded in 96-well plates and incubated for $18 \mathrm{~h}$ at $70-80 \%$ confluency. Then, the respective polymers were treated with polymers of various concentrations and incubated for $24 \mathrm{~h}$ in the presence of $10 \%$ serum. As presented in Figure 7, the PEI $25 \mathrm{kDa}$ ex-
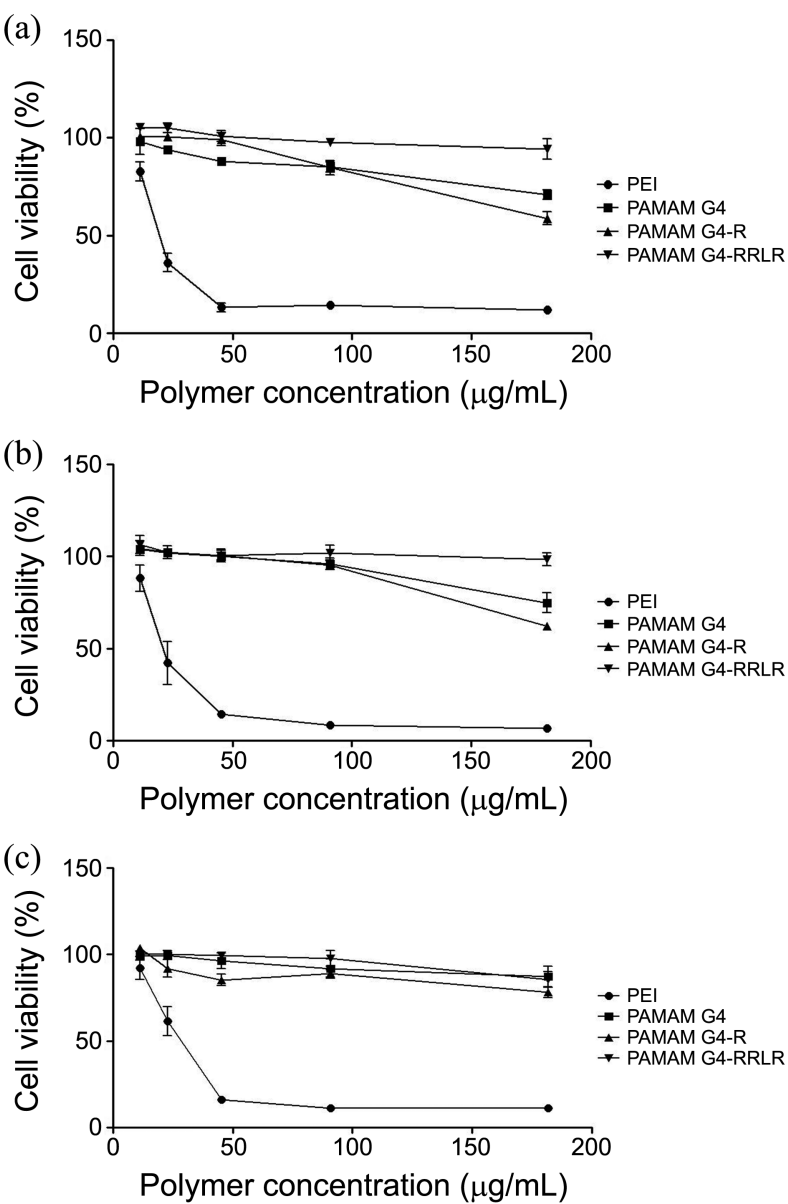

Figure 7. Cytotoxicity assay of PAMAM G4-RRLR. (a) HEK293, (b) NIH3T3 and (c) HeLa cells. Each value is the average and standard deviation from quadruplicates.

hibited higher cytotoxicity in all cell types tested, while the native PAMAM G4 and PAMAM G4-R showed low cytotoxicity. Interestingly, despite the treatment with an increased polymer concentration, PAMAM G4-RRLR showed low cytotoxicity in all cells, possibly due to its relatively low $\zeta$ potential value. The results indicate that the introduction of the RRLR on the peripheral ends of PAMAM generation 4 improves the gene transfection efficiency in HEK 293, NIH3T3, and HeLa cells. Although the mechanism underlying the function of PAMAM G4-RRLR remains unclear and has yet to be studied more, it is presumed that the enhanced transfection efficiency of PAMAM G4-RRLR is due to the increased localization of the complexes around nucleus followed by the facilitated penetration into cytoplasm.

Confocal Microscopy Experiment. To confirm the nuclear localization of pDNA by PAMAM G4-RRLR/pDNA polyplexes, we performed confocal microscopy using HeLa cells. Each of the polymers (PEI $25 \mathrm{kDa}$, PAMAM-G4, PAMAM G4-R and PAMAM G4-RRLR) was labeled with Alexa 488 and the pDNA was labeled with Alexa 532. All polymers were prepared at ratios optimal for transfection efficiency. As shown in Figure 8, the location of polymer was observed by green signal, and pDNA was identified by a red signal. Further, the nuclei were detected by a blue signal (Hoechst 


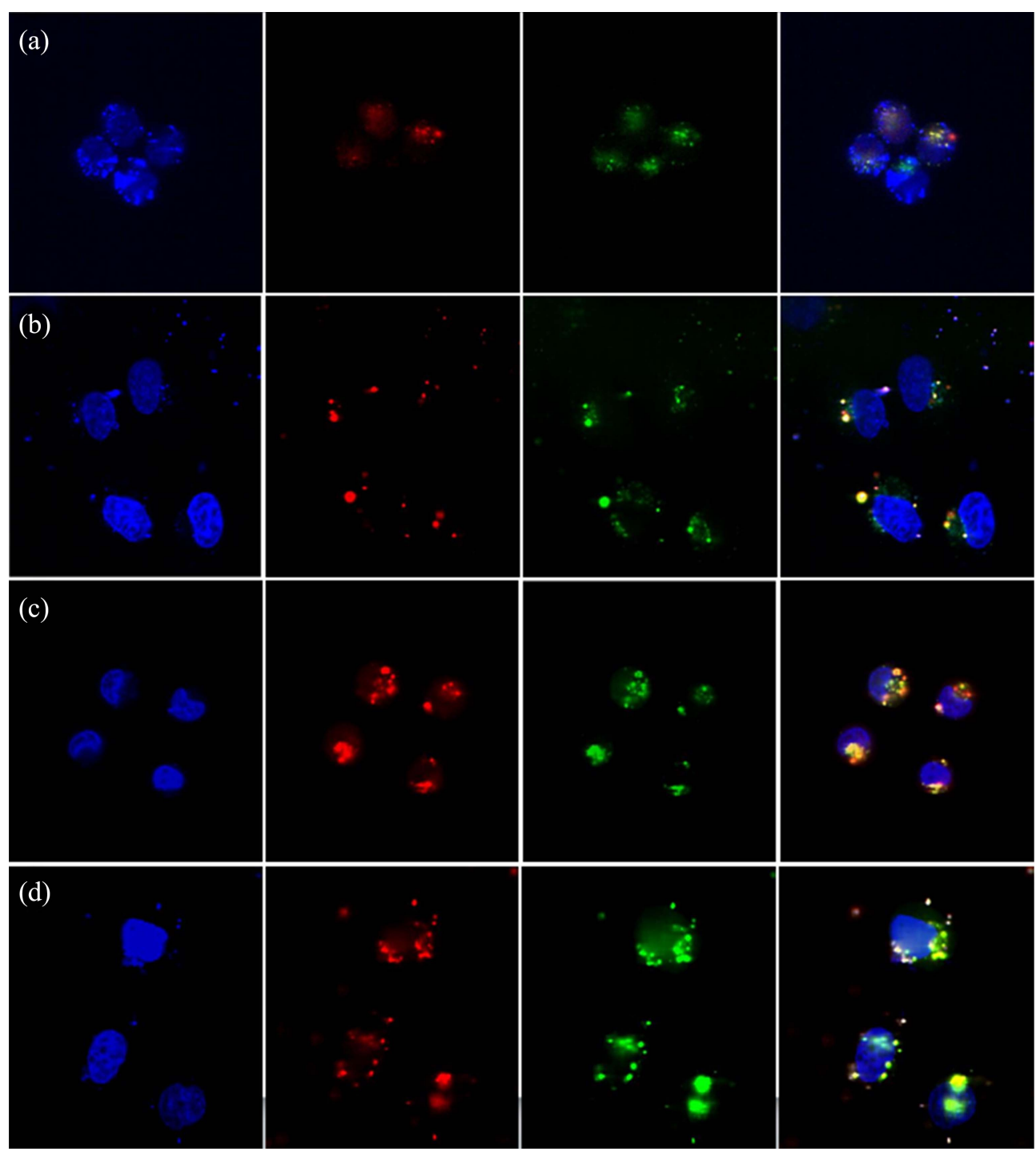

Figure 8. Confocal microscopy image of PAMAM G4-RRLR. (a) PEI25kDa, (b) PAMAM G4, (c) PAMAM G4-R and (d) PAMAM G4RRLR in Hela cells. Bisbenzimide (Hoechst 33342) was stained with nuclei (blue), Alexa 488-labelled polymer (green), Alexa 532-labelled pDNA (red) and the merged image.

33342). These results showed that PAMAM G4-RRLR polyplexes $(24: 1, \mathrm{w} / \mathrm{w})$ were translocated into the nuclei similarly or more efficiently than PEI $25 \mathrm{kDa}(2: 1, \mathrm{w} / \mathrm{w})$ and PAMAM G4-R (16:1, w/w) based transfections. This effective transfer of pDNA into the nuclei highlights the significance of conjugating NLS segment peptides to non-viral delivery vectors.

\section{Conclusions}

In this study, we synthesized a novel PAMAM generation 4 molecule with the NLS peptide (RRLR segment) on the peripheral ends of PAMAM generation 4 as a new non-viral gene delivery carrier and compared the performance of these novel molecules with PEI $25 \mathrm{kDa}$, a native PAMAM G4 and PAMAM G4-R by transfecting various cell lines. PAMAM G4-RRLR indicated similar transfection efficiency levels and exhibited no cytotoxic effects in all cell lines tested.
These results indicate that the introduction of NLS segment peptides on the PAMAM G4 may provide a promising nonviral gene delivery carrier for safe and effective gene therapy.

Acknowledgements. This study was supported by a grant from the Gene Therapy Project of the Ministry of Education, Science and Technology in the Republic of Korea (20120001118) and by the National Research Foundation of Korea Grant funded by the Korean Government (MSIP) (2013, University-Institute cooperation program).

\section{References}

1. Mintzer, M. A. ; Simanek, E. E. Chem. Rev. 2009, 109, 259.

2. Tang, Q.; Cao, B.; Wu, H.; Cheng, G. PLoS One. 2013, 8, E54460.

3. Choi, H.; Park, K. S.; Bae, S. J.; Song, S. J.; Kim, K. E.; Park, J. S.; Choi, J. S. Bull. Korean Chem. Soc. 2012, 33, 3676.

4. De Smedt, S. C.; Demmeester, J.; Hennink, W. E. Pharm Res. 2000, 17, 113 . 
5. Pack, D. W.; Hoffman, A. S.; Pun, S.; Stayton, P. S. Nat. Rev. Drug. Discov. 2005, 4, 581.

6. Haensler, J.; Szoka, F. C., Jr. Bioconjugate Chem. 1993, 4, 372.

7. Guillot-Niekowski, M.; Eisler, S.; Diederich, F. New J. Chem. 2007, 31,1111 .

8. Choi, J. S.; Ko, K. S.; Park, J. S.; Kim, Y. H.; Kim, S. W.; Lee, M. Int. J. Pharm. 2006, 320, 171.

9. Martin, M. E.; Rice, K. G. AAPS J. 2007, 9, E18.

10. Lee, J. I.; Jung, J. W.; Kim, Y. J.; Lee, E. J.; Choi, J. S. Int. J. Pharm. 2014, 459, 10.

11. Kiefer, P.; Acland, P.; Pappin, D.; Peters, G.; Dickson, C. EMBO J.
1994, 13, 4126.

12. Kim, T.-H.; Choi, H.; Yu, G. S.; Lee, J.; Choi, J. S. Macromol. Res. 2013, 21, 1097.

13. Xu, D.-M.; Yao, S.-D.; Liu, Y.-B.; Sheng, K.-L.; Hong, J.; Gong, P.-J.; Dong, L. Int. J. Pharm. 2007, 338, 291.

14. Tang, Q.; Cao, B.; Wu, H.; Cheng, G. Langmuir. 2012, 28, 16126.

15. Shcharbin, D.; Pedziwiatr, E.; Bryszewska, M. J. Controlled Release 2009, 135, 186.

16. Tang, M. X.; Szoka, F. C. Gene Ther. 1997, 4, 823.

17. Choi, J. S.; Nam, K. H.; Park, J.-y.; Kim, J.-B.; Lee, J.-K.; Park, J.-s. J. Control. Rel. 2004, 99, 445. 